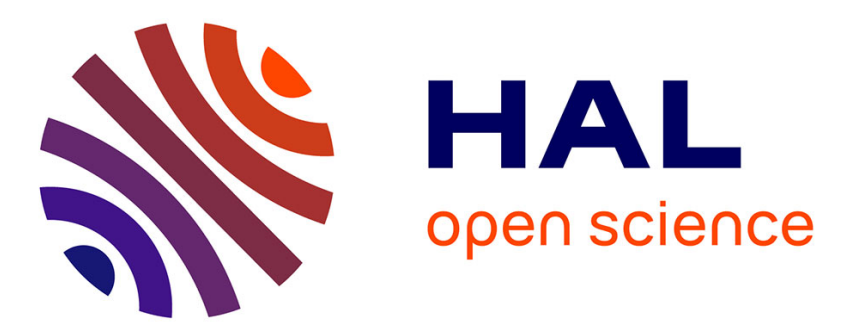

\title{
Varroa destructor rearing in laboratory conditions: importance of foundress survival in doubly infested cells and reproduction of laboratory-born females
}

Vincent Piou, Angélique Vétillard

\section{- To cite this version:}

Vincent Piou, Angélique Vétillard. Varroa destructor rearing in laboratory conditions: importance of foundress survival in doubly infested cells and reproduction of laboratory-born females. Apidologie, In press, 51 (6), pp.968-983. 10.1007/s13592-020-00775-0 . hal-03277732

\author{
HAL Id: hal-03277732 \\ https://hal.science/hal-03277732
}

Submitted on 5 Jul 2021

HAL is a multi-disciplinary open access archive for the deposit and dissemination of scientific research documents, whether they are published or not. The documents may come from teaching and research institutions in France or abroad, or from public or private research centers.
L'archive ouverte pluridisciplinaire HAL, est destinée au dépôt et à la diffusion de documents scientifiques de niveau recherche, publiés ou non, émanant des établissements d'enseignement et de recherche français ou étrangers, des laboratoires publics ou privés. 


\title{
Varroa destructor rearing in laboratory conditions: importance of foundress survival in doubly infested cells and reproduction of laboratory-born females
}

\author{
Vincent Piou, Angélique VÉTILLARD \\ Laboratoire Evolution et Diversité Biologique,UMR5174, PRES-Université de Toulouse, Institut National Universitaire \\ Champollion, Albi, France
}

Received 29 July 2019 - Revised 2 April 2020 - Accepted 28 May 2020

\begin{abstract}
A considerable part of the knowledge about the honey bee parasite Varroa destructor emerged from rearing protocols in semi-natural or laboratory conditions, yet a durable protocol over several generations of mites is still lacking. The development of such multigenerational rearing relies on the emergence of a sufficient number of new fertile females in the first generation of $V$. destructor. The optimization of the parasite's reproductive success in laboratory conditions thus represents an important prerequisite. The number of foundress mites in a cell is known to impact the probability of male survival and thus the number of mated daughters. We therefore investigated the effect of the degree of bee larvae infestation under laboratory conditions. The results showed that the probability of finding at least one foundress alive at the end of the rearing was significantly higher in doubly infested cells. This leads to the improvement of the reproductive parameters and more specifically of the number of daughters per mite. In doubly infested cells with one dead foundress, the presence of a surviving female would in fact allow both its descendants and those of the dead mite to complete their development. The mated daughters from this system were used in a subsequent experiment to test their ability to complete their reproductive cycle in laboratory conditions, from the perspective of developing a multigenerational rearing. The reproduction and development of the offspring measured were similar to those of the first generation. However, many of the females from the second generation died before the completion of their first reproductive cycle. We suggest that these females are fertile but might lack the energy necessary to survive throughout reproduction. The results from our bioassay could constitute a basis for the development of a durable $V$. destructor laboratory rearing and for the improvement of our understanding of the parasite's reproductive cycle.
\end{abstract}

Varroa destructor / Parasite / Mite / Laboratory rearing / Double infestation / Multigenerational

Electronic supplementary material The online version of this article (https://doi.org/10.1007/s13592-020-00775-0) contains supplementary material, which is available to authorized users.

Corresponding author: A. Vétillard, angelique.vetillard@univ-jfc.fr

Manuscript Editor: Yves Le Conte Contributions

VP and AV conceived this study, VP designed and performed the experiments, analysed the results and wrote the manuscript. AV participated in the redaction and revision of the article.

\section{INTRODUCTION}

Modern beekeeping suffers from a global colony weakening which manifests itself through winter losses and unexplained colony collapses each year (Neumann and Carreck 2010). Many causes are highlighted by the scientific community, which includes pesticide use, predators, pathogens, and parasites (Oldroyd 2007; Le Conte et al. 2010; Goulson et al. 2015). The main ectoparasite of the Western honey bee Apis mellifera $\mathrm{L}$ is the acarian Varroa destructor (Anderson and Trueman) (Nazzi and Le Conte 2015). This 
parasite switched host from the Asian to the Western species of honey bee in the beginning of the twentieth century and has now spread worldwide (Solignac et al. 2005). Its close association with many honey bee viruses makes $V$. destructor one of the major causes of colony loss (Martin 2001; Guzmàn-Novoa et al. 2010; Francis et al. 2013).

The cycle of $V$. destructor is divided into two distinct phases: a parasitic phase on adults called the phoretic phase and a parasitic phase on larvae and pupae during which the females reproduce (Rosenkranz et al. 2010). More precisely, the reproduction of $V$. destructor starts $70 \mathrm{~h}$ after the sealing of a larval cell infested by the parasite. At this point, the females lay a first haploid male egg (Rehm and Ritter 1989; Donzé and Guerin 1994; Martin 1994). Every 30 h, the mites then lay a series of diploid female eggs. The eggs hatch and the juveniles go through their larval development, from protonymphs to deutonymphs that molt to become adults (Martin 1994). Once the male and the first female reach the adult stage, mating occurs within the sealed cell. The male mostly mates with the younger adult females, and multiple mating events are frequent (Ziegelmann et al. 2013). When the bee finally emerges from the sealed cell, the newly mated females and the foundress can infest adult hosts to start a new parasitic cycle (Martin and Kemp 1997). An important part of the knowledge concerning the parasitic mite emerged from the study of $V$. destructor in laboratory or seminatural conditions (Le Conte et al. 1989; Donzé and Guerin 1994; Rosenkranz et al. 2010; Frey et al. 2013; Ziegelmann et al. 2013). These experimental methods enable control over many parameters such as the temperature and hygrometry, along with facilitated observation of the parasite cycle.

The laboratory settings that allowed the precise description of the parasite cycle are diverse. The protocols actually range from the simple transfer of frames under controlled conditions (Donzé and Guerin 1994) to completely artificial feeding chambers (Tabart et al. 2013), including the use of gelatine capsules to simulate brood cells (Nazzi and Milani 1994). This system developed by Nazzi and Milani (1994) and used in recent studies (Piou et al. 2016; Annoscia et al. 2017;
Mondet et al. 2018) is particularly promising. Indeed, this protocol can benefit from the control over many parameters and from the possibility to follow the parasite cycle in a daily manner without significantly impacting the physiology of mites (Piou et al. 2016; Mondet et al. 2018). However, to our knowledge, this method remains limited to one generation of mites, and a multigenerational rearing is still lacking. To develop a functional second generation rearing, the first concern is to optimize the reproductive success of the foundresses from the first generation reared in the laboratory to ensure the production of numerous fertile daughters.

The aim of this study was thus to explore ways to improve the efficacy of rearing protocols of mites collected in bee colonies to then test for the first time the rearing of their daughters born under laboratory conditions. The parameter we chose to enhance the reproductive success of mites is the infestation level of cells. In most cases, a single female foundress infests the cell. However, multiple infestations can also happen, especially in autumn when the parasite population is high (Martin 1995; Donzé et al. 1996; Beaurepaire et al. 2017). Even if several studies showed that multiple infestations tend to decrease the number of offspring per mite (Fuchs and Langenbach 1989; Eguaras et al. 1994), the proportion of cells with living males and thus the number of mated females is expected to be higher when double infestations occur (Martin 1995; Donzé et al. 1996). Our aim was to investigate the reproductive outcome of $V$. destructor reared in singly and doubly infested cells in order to understand if double infestation could indeed increase the proportion of mated daughters per foundress. The potentially mated daughters from this first experiment were collected, and their reproductive capacity was assessed in a second rearing only using the females born under laboratory conditions.

\section{MATERIAL AND METHODS}

Eight honey bee colonies derived from Buckfast and Carniolan origins were used in this study conducted between July and September 2018. The colonies were maintained on the 
University campus in Albi (France) and occasionally fed sucrose syrup. The ethical recommendations currently in force in the European Union were followed. The colonies were left untreated so that the $V$. destructor population remained high enough during our experiments.

\subsection{General rearing procedure}

In order to simulate a phoretic phase under laboratory conditions, adult worker bees were collected in colonies on an open brood frame, kept in experimental cages (Pain 1966), and fed ad libitum with a $50 \%$ sucrose syrup solution. On the same day, foundress mites randomly sampled from sealed brood cells were transferred onto the collected adult bees kept in experimental cages. The cages were placed in an incubator $\left(34.5{ }^{\circ} \mathrm{C}, 60 \% \mathrm{RH}\right)$ for 3 days to simulate a phoretic phase. We chose a 3-day duration based on its occurrence in natural conditions and on a previous work that showed that a longer phoretic phase did not improve the outcome of the parasite's reproduction (Boot et al. 1993; Piou et al. 2016).

On the third day, the phoretic mites were transferred onto fifth instar larvae so that they could start their reproduction. To do so, an open brood frame, ideally containing a high proportion of larvae, was taken to the laboratory. Bottom halves of gelatine capsules ( $0.3 \mathrm{~mL}$, LGA, La Seyne-surMer - France) were placed on the fifth instar larval cells before their sealing. The frames were then arranged horizontally, with the capsules pointing down, in a $34.5{ }^{\circ} \mathrm{C}$ incubator for 2 to $5 \mathrm{~h}$. The transfer of larvae in the capsules thus only relied on the spinning movements and did not involve any handling. Once the larvae were transferred, the capsules were removed from the frame, and the parasitized adult worker bees kept in cages were $\mathrm{CO}_{2}$-anesthetized for one minute. The female mites were collected from the anesthetized adults and placed on the larvae in the capsules, as described in Piou et al. (2016). The gelatine capsules containing the parasites and the larvae were closed and kept at $34.5{ }^{\circ} \mathrm{C}, 80 \% \mathrm{RH}$ in an incubator until the emergence of the bee around the 12th day.

\subsection{Impact of double infestation}

The general procedure recreating the parasite cycle was followed as described above. For the laboratory phoretic phase of the infestation level bioassay, 100 adult bees randomly sampled on an open brood frame were artificially parasitized with randomly collected $V$. destructor females. On the third day, before being placed in gelatine capsules containing larvae, the mites were marked on their dorsal scutum using a thin paint pen (Posca $\left.{ }^{\mathrm{TM}}\right)$. The effect of marking with a paint pen on the survival and reproduction of the parasite was assessed by including unmarked mites in our rearing and then considering the marking in the statistical analyses. To study the effect of double infestation in laboratory conditions, the capsules were separated into two treatments: either infested with a single parasite or infested with two parasites. This rearing was repeated twice by colony on a total of 209 female mites and 150 bee pupae, among which 59 were doubly infested. The capsules in which the larvae did not survive the prepupal stage were discarded. This mortality seems to be a consequence of the transfer process rather than parasitization, as shown by the similar mortality rates obtained when larvae were transferred without mites (Online resource 1). The 185 mites and 132 bees that started the pupal phase were recovered at the end of the 12 days, and the proportion of capsules with at least one living foundress was noted. The proportion of capsules in which reproduction was initiated-i.e., with observable eggs, protonymphs, deutonymphs, or freshly molted adults - was also measured. In each cell, the number of protonymphs, deutonymphs, and daughters per foundress was assessed, along with the presence and number of males. The different parameters measured in the infestation level bioassay are summarized in Table I. When living males were observed in capsules where the reproductive foundresses were marked, the living mature daughters, easily identifiable as they had no paint on their dorsal scutum, were considered potentially mated and collected for the second generation rearing. 
laboratory rearing of Varroa destructor

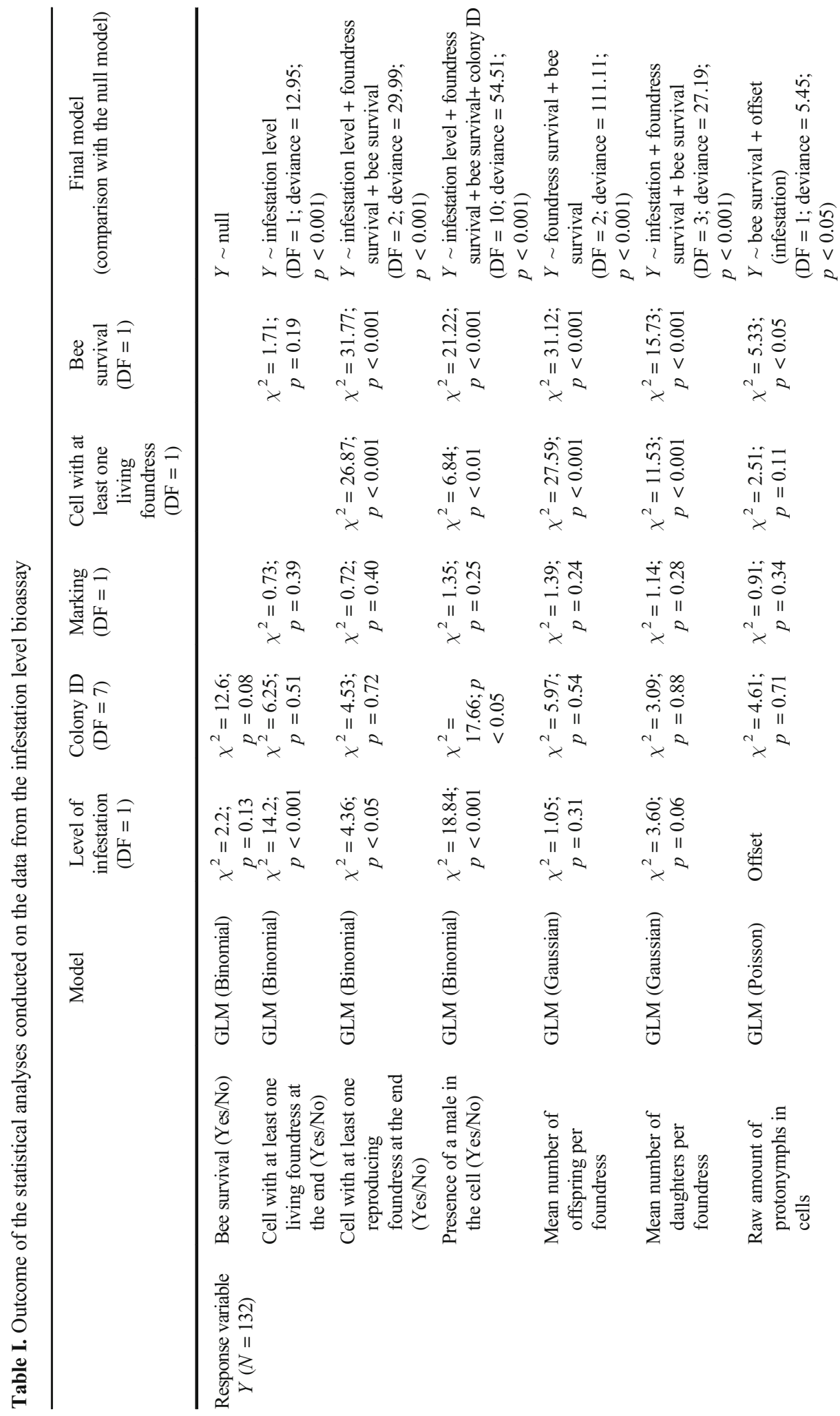




\subsection{Second generation rearing}

In this rearing, only the adult female mites born under laboratory conditions were used. The potentially mated daughters from single and double infestation treatments were collected and pooled together. They were transferred onto 50 newly sampled adult bees kept in experimental cages. In this experiment, the sampling of adult bees for the phoretic phase was more rigorous, and only worker bees on which no parasitic mite was observed were collected and placed in the cages. This was necessary to not bias the second generation rearing with mites from the colonies. The general procedure was then followed, and the reproductive phase was initiated 3 days later when one mite was transferred into a gelatine capsule containing a bee larva. This second generation rearing was repeated six times to reach the total of 48 daughter mites. Again, the capsules in which the larva did not survive the first 2 days after the transfer were discarded (Online resource 1). On the 12th day, the survival of mites and of bee pupae was assessed. The reproductive rate of foundresses, regarded as the proportion of mites that initiated their reproduction, was measured. The number of offspring (protonymphs, deutonymphs, and daughters) per foundress was also counted.

\subsection{Statistical analysis}

\subsubsection{Dependent variable analyzed}

The data were statistically analyzed using $\mathrm{R}$ 3.4.3 ( $\mathrm{R}$ Core Team 2017). The graphs were obtained using the ggplot2 package from the $\mathrm{R}$ software (Wickham 2009). Generalized linear models (GLMs) were conducted to analyze the data. Survival and reproductive proportions were analyzed as binary variables (with a Yes/No response), whereas offspring were numbered and treated as count data. The final model retaining only the significant parameters was finally compared with the null model (Crawley 2013) (Tables I and II). 


\subsubsection{Parameters included in the infestation level analysis}

When normality and homoscedasticity conditions were confirmed, the mean number of offspring per female was analyzed and included in a Gaussian regression (Table I). As it was not the case for the mean amounts of deutonymphs, protonymphs, and males, Poisson regressions were used on the raw count data and the infestation level was included as an offset variable. Along with the level of infestation, the presence of a surviving foundress at the end of the rearing and the survival of bees were also tested to explain part of the variability of the measured reproductive and survival features. The colony ID parameter-allowing the identification of the colony from which bees and parasites were collected-was included in the model as it can be a source of variability. The paint marking was tested to make sure that it did not lead to a significant bias in the results. Precisions about the parameters fitted in each model are brought in Table I.

Finally, in order to examine further the link between infestation level and proportion of potentially mated daughters, a GLM analysis of the percentage of cells with living males was performed on a subset of the data containing only the capsules in which living daughters were observed.

\subsubsection{Parameters included in the second generation-rearing analysis}

The data regarding the second generation were compared with the observation of the first generation from singly infested cells only. The survival of the bee, the generation, and the survival of the foundress were the parameters tested to explain our response variables (Table I). In the cells where foundress mites produced daughters that had matured into adults at the time of our observation, the number of surviving daughters was analyzed with the generation and the survival of the mother as explanatory factors.

\section{RESULTS}

\subsection{Impact of double infestation}

\subsubsection{Host and parasite mortality}

The mortality rate of bees did not vary much when a second mite was introduced into the capsules. No significant difference was found in the survival of bee pupae infested with two mites (94.3\% (CI 95, 84.3-98.8)) or one mite $(94.9 \%$ $(\mathrm{CI} 95,87.5-98.6))\left(\mathrm{GLM} \chi^{2}=2.2 ; \mathrm{DF}=1 ; p=\right.$ 0.13; Table I).

Regarding the parasite mortality, as expected in a low competition context, the proportion of capsules with at least one living foundress at the end of the experiment was positively impacted by the infestation level (GLM $\chi^{2}=14.2 ; \mathrm{DF}=1 ; p<$ 0.001, Table I). More precisely, 98.1\% (CI 95, 89.9-99.9) of the capsules contained at least one survivor in the case of double infestation and 78.5\% (CI 95, 67.8-86.9) when only one mite infested the artificial cell (Figure 1). The difference between infestation levels is obviously due to the fact that, in a context of low competition, adding a mite in the cell increases the probability of observing at least one survivor on the 12th day. When individual mortality is considered, the survival rate in doubly infested cells actually decreases to $87.7 \%$ (CI 95, 79.9-93.3). On the other hand, the survival of bees (GLM $\chi^{2}=1.71 ; \mathrm{DF}=$ $1 ; p=0.19)$, the marking (GLM $\chi^{2}=0.73$; $\mathrm{DF}=$ $1 ; p=0.39$ ) or the colony ID (GLM $\chi^{2}=6.25$; $\mathrm{DF}=7 ; p=0.51$ ) did not significantly impact the proportion of cells with one living foundress (Table I).

\subsubsection{Reproduction of the parasite}

The proportion of capsules in which reproduction was initiated is significantly different between infestation treatments (two mites 94.34\%; one mite, 75.95\%; GLM $\chi^{2}=4.36$; $\mathrm{DF}=1 ; p<$ 0.05 ; Figure 1, Table I). Adding one mite in the capsules increases the probability of observing reproduction in the cells at the end of the 12-day cycle. The presence of a living foundress on the 12th day $\left(\mathrm{GLM} \chi^{2}=26.87 ; \mathrm{DF}=1 ; p<0.001\right)$ and the survival of the bee (GLM $\chi^{2}=31.77$; DF 


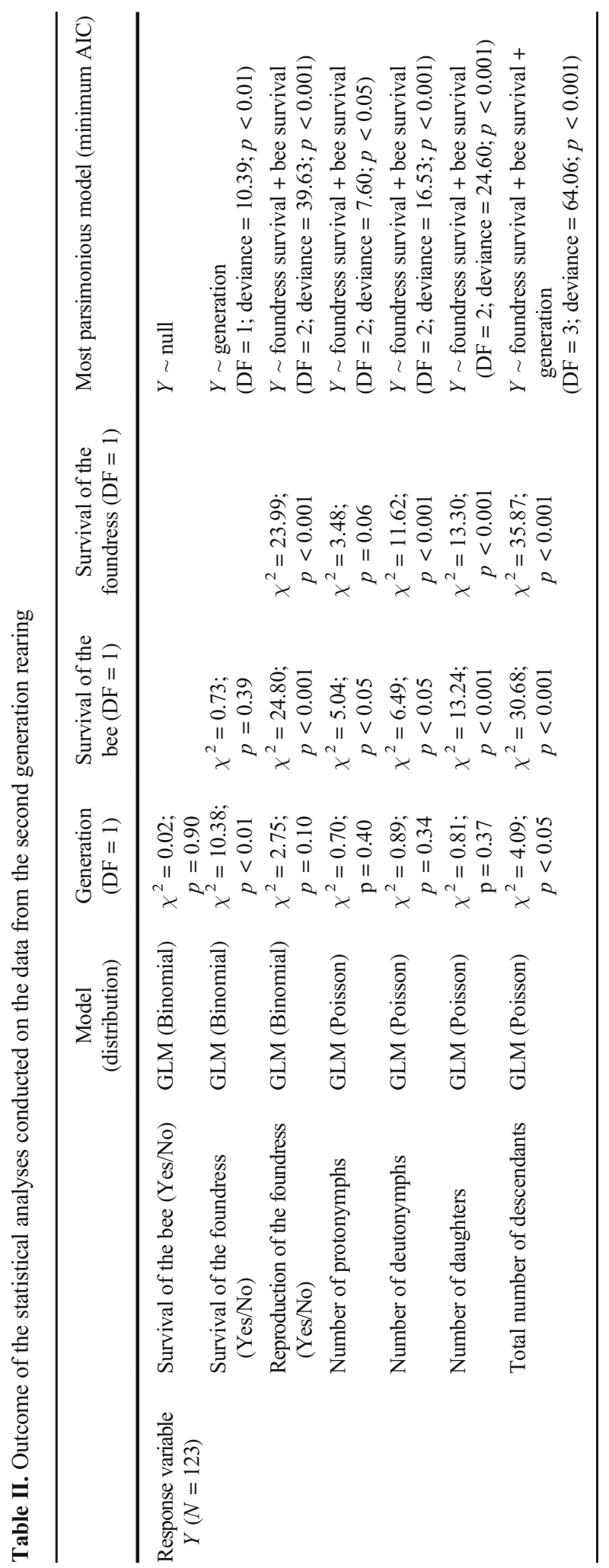




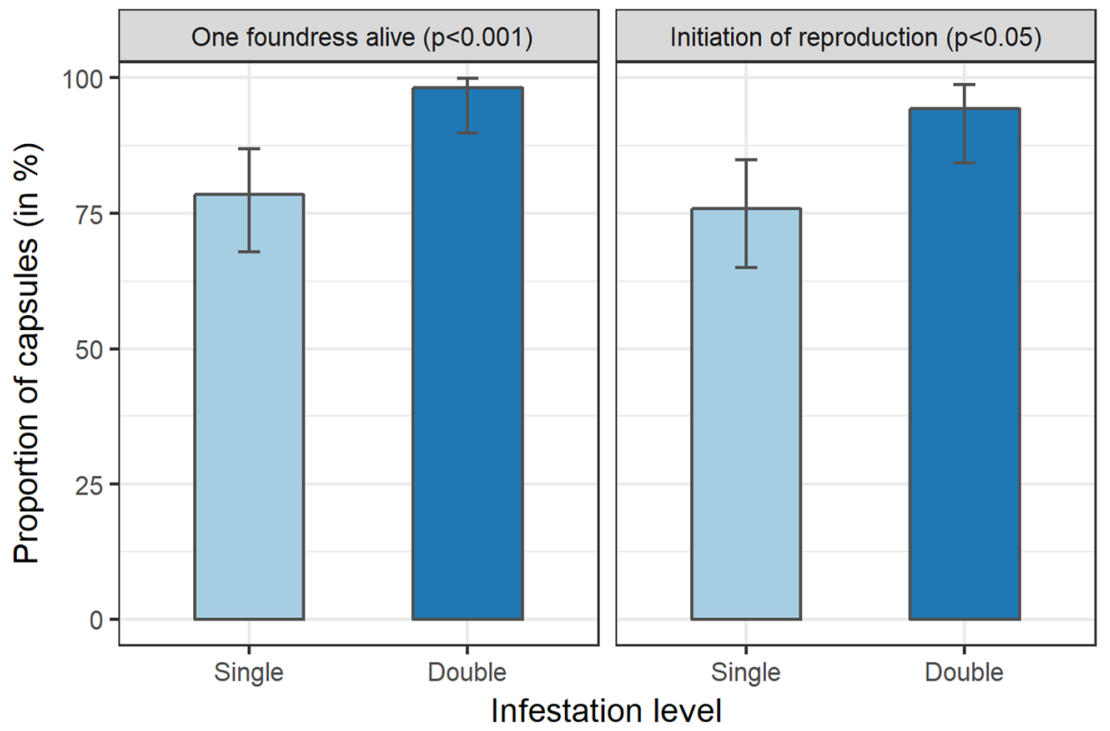

Figure 1. Proportion (and 95\% confidence intervals) of capsules with at least one foundress alive (left) and proportion of capsules in which reproduction was initiated (right) in double or single infestation. The differences between infestation treatments are significant for both dependent variables (foundress alive, $\mathrm{DF}=1, \chi^{2}=14.2, p<$ 0.001 ; initiation of reproduction, $\mathrm{DF}=1, \chi^{2}=4.36, p<0.05$ ).

$=1 ; p<0.001)$ also significantly impact this probability (Table I). Even when only the surviving foundresses are considered, reproduction occurs slightly more often in doubly $(94.23 \%)$ than in singly infested cells $(88.71 \%)$.

Regarding the total number of offspring per foundress, differences are observable between single and double infestations. More precisely, the average number of offspring per foundress is higher in capsules infested with two parasites $(2.74 \pm 0.15)$ than in capsules infested with one parasite only $(2.23 \pm 0.21)$. Even though no significance was detected between infestation treatments $\left(\mathrm{GLM} \chi^{2}=1.05 ; \mathrm{DF}=1 ; p=0.31\right)$, this appears to be indirectly linked to the infestation parameter. Indeed, the number of offspring depends on the presence of at least one living foundress on the 12th day (GLM $\chi^{2}=27.59$; $\mathrm{DF}=1 ; p<0.001$, Table I) which is significantly higher in the case of double infestation. A similar situation was noted with the number of deutonymphs, males, and in particular with the number of daughters (Table I, Figure 2a). More precisely, $1.41 \pm 0.10$ daughters per foundress are on average observed in doubly infested cells against $0.99 \pm 0.13$ in the case of single infestation (among which $0.63 \pm 0.12$ were alive and mated at the end of the experiment). However, the statistics show again that the presence of a surviving foundress rather than the infestation level significantly impacts the number of daughters. The infestation level parameter was still retained in the final model as it shows a tendency to significance $\left(\right.$ GLM $\chi^{2}=3.60 ; \mathrm{DF}=1 ; p=0.06$; Table I, Figure $2 \mathrm{a}$ ). The only reproductive feature not impacted in the same way is the number of protonymphs which is higher in the single infestation treatment. However, the analysis showed that the number of protonymphs only depends significantly on the bee survival (GLM $\chi^{2}=$ 5.53; DF $=1 ; p<0.05)$. Although it affects a restricted number of cells $(7 / 132)$, the bee pupa survival factor is obviously important as it reduces the probability of parasite reproduction. That is why it was retained in the majority of final models (Table I).

Finally, regarding the link between infestation level and proportion of males in cells (and consequently of mated adult daughters), the results show that males are more frequently observed in doubly $(75.47 \%$ (CI 95, 61.72-86.25)) than in singly infested capsules $(46.38 \%$ (CI 95, 29.60- 
a)

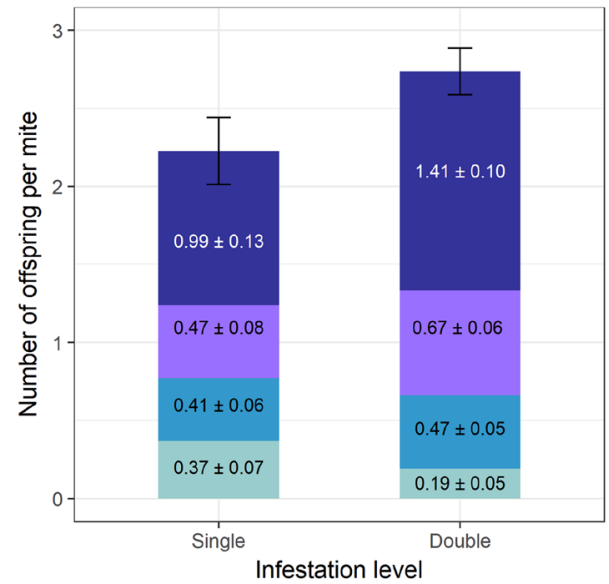

b)

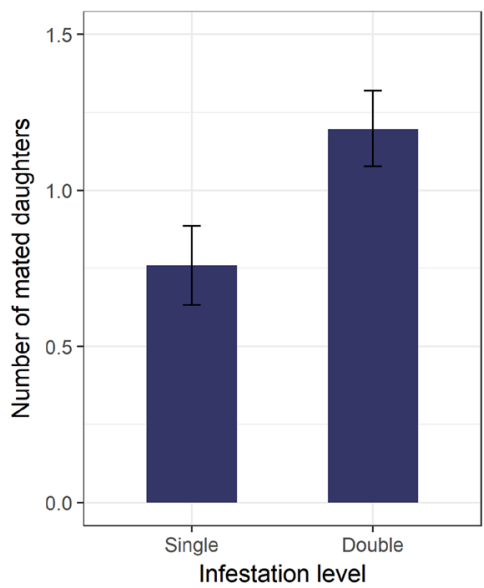

Figure 2. a For each category of offspring, mean number of individuals ( \pm standard error) observed per foundress in the case of single or double infestation. The differences observed between infestation treatments are not directly due to the infestation level but are significantly dependent on the proportion of capsules with one living foundress, which is higher in the case of double infestation (Table I). b Mean number of potentially mated daughters per foundress ( \pm SE) in singly or doubly infested cells. The difference observed is related to the higher number of daughters per foundress in doubly infested cells ( $\mathrm{DF}=1, \chi^{2}=3.60, p=0.06$ ) and to the presence of a living male, also more frequent in doubly infested cells ( $\mathrm{DF}=1, \chi^{2}=18.84, p<0.001$; Table I).

52.15); $p<0.001$; Table I). This could lead to the higher mean of mated daughters per foundress in doubly infested cells (Figure 2b). However, when the same analysis is run exclusively on the cells in which living daughters were noticed, the difference between infestation treatments is reduced (73.33\% (CI 95, 67.95-91.99) and 75.76\% (CI $95,57.74-88.91))$, and only a trend toward significance is detected $\left(\mathrm{GLM} \chi^{2}=3.01 ; \mathrm{DF}=1 ; p\right.$ $=0.08)$.

\subsection{Second generation rearing}

\subsubsection{Host and parasite mortality}

In singly infested cells, the second generation rearing resulted in a comparable bee survival rate with 95.46\% (84.53-99.44) surviving pupae while the survival reached $94.94 \%(87.54-$ 98.60) in the first generation (GLM $\chi^{2}=0.02$; $\mathrm{DF}=1 ; p=0.90$, Table II). In contrast, the survival rate of the parasite significantly dropped in the second generation $\left(\mathrm{GLM} \chi^{2}=10.38\right.$; DF $=$ $1 ; p<0.01)$. The laboratory-born females used in the second generation died in $50 \%$ of the cells during their first reproductive cycle (Figure 3a, Table II).

\subsubsection{Reproductive parameters}

Surprisingly, despite the $50 \%$ mortality of foundresses in the second generation rearing, the proportion of reproductive mites remained similar to the values measured in singly infested cells from the first generation $\left(\mathrm{GLM} \chi^{2}=2.75\right.$; DF $=$ $1 ; p=0.10$; Figure $3 \mathrm{a}$, Table II). The reproduction was only significantly impacted by the survival of the foundress (GLM $\chi^{2}=23.99$; DF $=1 ; p<$ $0.001)$ and of the bee (GLM $\chi^{2}=24.80 ; \mathrm{DF}=1$; $p<0.001$, Table II). When only the surviving foundresses are considered, the difference is slightly more pronounced and the reproduction reached $81.82 \%$ in the second generation, compared with $88.71 \%$ in the first.

The number of protonymphs $(0.41 \pm 0.11)$, deutonymphs $(0.48 \pm 0.10)$, and adult daughters $(0.98 \pm 0.10)$ per foundress were all similar and not significantly affected by the generation factor (Table II). Only the survival parameters of the foundress and of the bee pupa had a significant 


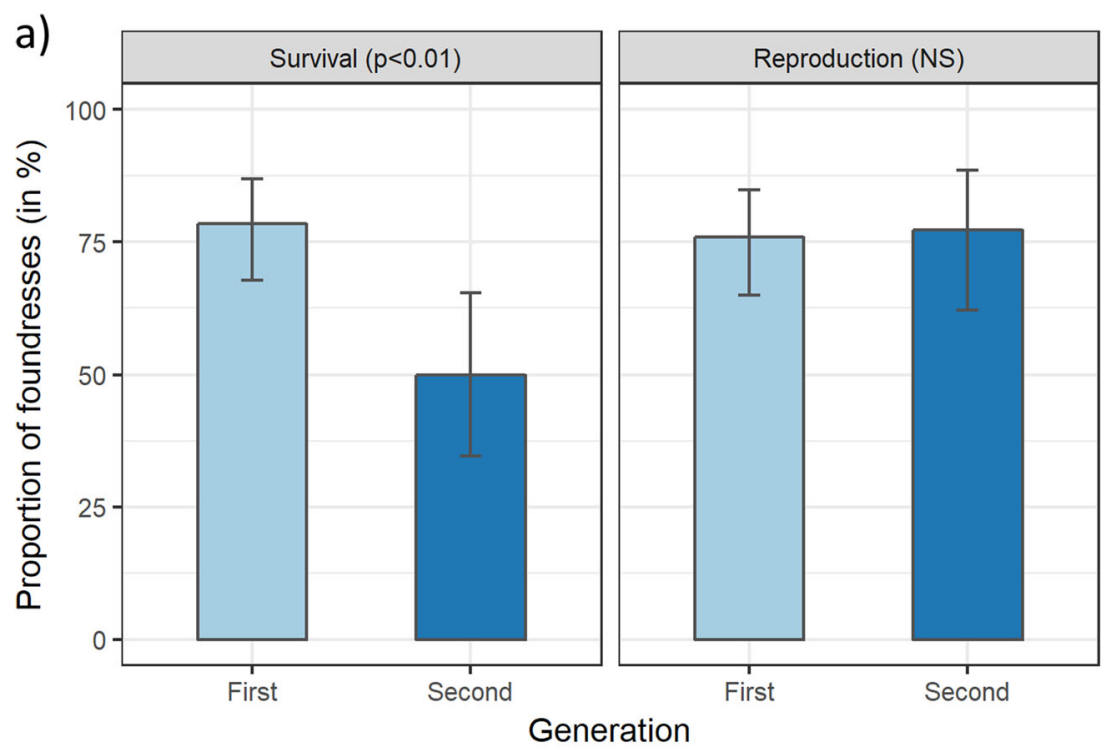

b)

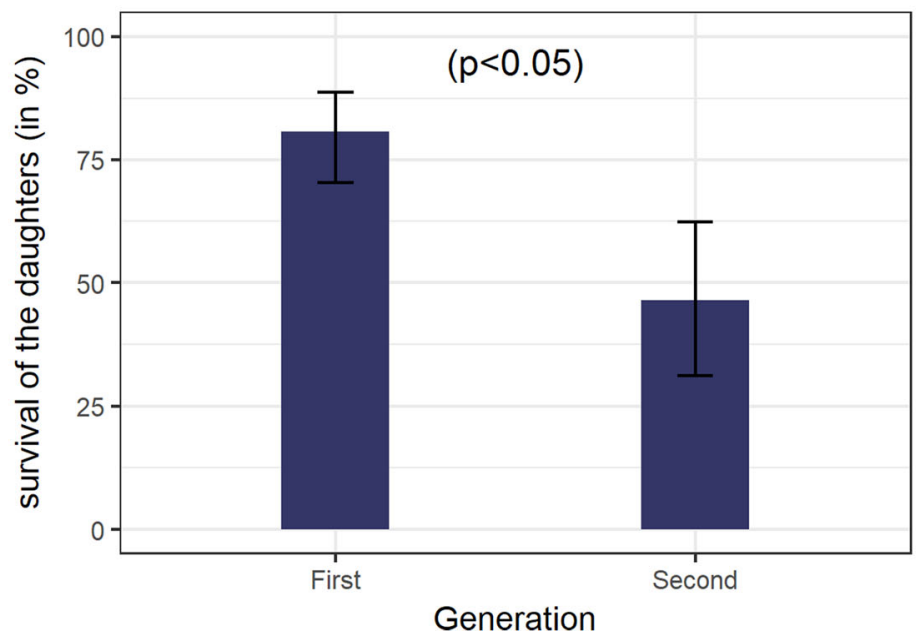

Figure 3. a Survival or reproduction of the female mites in singly infested cells in relation to the generation reared under laboratory conditions. The error bars represent the 95\% confidence intervals. The differences between generations are significant in the case of the survival $\left(\mathrm{DF}=1, \chi^{2}=10.38, p<0.01\right)$ and not significant when it refers to oviposition ( $\mathrm{DF}=1, \chi^{2}=2.75, p=0.10$ ). b Survival of the daughters $V$. destructor that reached the adult stage in relation to the generation of mites reared under laboratory conditions. The error bars represent the $95 \%$ confidence intervals. The difference is significantly related to the generation (GLM, DF $=1, \chi^{2}=5.13, p<0.05$ ).

impact. Again, it should be noted that the bee survival parameters only affected a limited number of replicates (six out of 124).

The total number of offspring was the sole dependent variable significantly impacted by the generation $\left(\mathrm{GLM} \chi^{2}=4.09 ; \mathrm{DF}=1 ; p<0.05\right)$, although the difference between generations is very low $(2.23 \pm 0.21$ in the first generation and $2.36 \pm 0.28$ in the second). Most of the variation is in fact due to the offspring count in the 39 cells in which the foundress died before the 12th day (with a mean of $0.65 \pm 0.33$ offspring for the first generation against $1.73 \pm 0.36$ for the second). This confirms that the dead foundresses in the 
second generation died at a more advanced stage of their reproductive cycle. The parasite survival parameter also significantly affected the offspring counts $\left(\mathrm{GLM} \chi^{2}=35.87\right.$; DF $=1 ; p<0.001$; Table II).

Finally, in the 68 cells where the foundresses successfully reproduced and generated one or several daughters, the survival of these daughters was significantly dependent on the generation and, more precisely, lower in the second generation $\left(\mathrm{GLM} \chi^{2}=5.13 ; \mathrm{DF}=1 ; p<0.05\right.$; Figure $3 \mathrm{~b}$ ). The survival of the daughters also had a tendency to be positively related to the survival of the foundress (GLM $\chi^{2}=3.37$; DF $=1 ; p=0.07$ ).

\section{DISCUSSION}

\subsection{On the general laboratory rearing protocol in singly infested cells}

When compared with data from the literature, our rearing of mites in singly infested gelatine cells leads to relatively similar reproductive features. Even when the dead foundresses are included in the analysis, the reproduction rate obtained in this study reached $75.95 \%$ which remains within the range of values encountered in other studies on European varieties of honey bee, from around 60 (Nazzi and Milani 1994; Martin et al. 1997) to 80 or $90 \%$ (Ifantidis 1984; Fuchs and Langenbach 1989; Harris et al. 2010; Piou et al. 2016). The same conclusions can be drawn from the number of mature daughters (0.99) and mated daughters (0.75) as Donzé et al. (1996) obtained respectively a mean of 1.07 mature and 0.83 mated daughters per foundress in controlled conditions. These values, along with the average number of 0.63 living mated daughters per foundress found in our study are a bit low but remain within the range of in vivo studies. Indeed, if several studies in natural conditions described higher reproductive successes (Ifantidis 1984; Fuchs and Langenbach 1989; Martin 1994; Odemer 2020), our results are close to the data obtained by Lin et al. (2018) and even higher than many studies on Apis mellifera scutellata
(Calderón et al. 2010, 2012; Nganso et al. 2018). One essential difference that could be involved in the divergence between laboratory and in vivo studies is the presence of adult bees. In naturally resistant honey bees, the presence of workers is indeed known to reduce the proportion of fertile mites (Harbo and Harris 2009; Oddie et al. 2018). However, in susceptible colonies, the presence of workers has a low effect on the reproductive rate (Harris et al. 2010), and the removal of pupae with abnormal development could even lead to an overestimation of the number of offspring (Lin et al. 2018). The number of mated daughters per female is also impacted by the low survival of male offspring in our study which is close to the male survival rate in Africanized bees (Medina and Martin 1999). This high mortality could be due to the fact that our laboratory rearing enables measurements at emergence rather than at a late pupal stage as in many in vivo studies. Emergence involves many mortality risks to the males and immature stages especially because of the frequent movements of the bee. Besides this methodological difference, resistance mechanisms of the bee pupae could also lead to such reduced mite reproduction, resulting in low amounts of mated daughters per foundress, as suggested in A. mellifera scutellata (Calderón et al. 2012; Nganso et al. 2018). Even in European colonies, the genetic and geographic origins of bees can have an important impact on the parasite's reproduction, and local resistance mechanisms can lead to a reduced reproductive outcome (Locke et al. 2012; Oddie et al. 2018). Altogether, despite diverse designs and many sources of variation between studies, it seems that laboratory rearing using gelatine capsules is an appropriate method to mimic the natural reproduction conditions of V. destructor (Nazzi and Milani 1994; Piou et al. 2016; Egekwu et al. 2018). Until now, these protocols in controlled conditions only focused on a single generation of mites. The development of a multigenerational rearing depends on the optimization of the reproduction in these rearing systems. The presence and fertility of daughter mites born under 
laboratory conditions are indeed a prerequisite for the development of such a rearing protocol over several generations.

\subsection{Impact of double infestation and optimization of the reproductive success}

Multiple infestation events of $A$. mellifera larval cells by $V$. destructor are common, and up to five or six foundress mites can be found in one worker cell (Eguaras et al. 1994; Martin 1995; Donzé et al. 1996). Double and single infestations remain the most frequent cases and the effect of a supplementary mite in a cell has drawn the attention from scientists. Both reductions (Fuchs and Langenbach 1989; Boot et al. 1997) and increases (Donzé et al. 1996) of the number of daughters per female were observed in the presence of a second mite. In the study of Donzé et al. (1996), the number of mated daughters was higher in doubly (1.07) than in singly infested cells (0.83). The hypothesis was that the presence of a second foundress could improve the reproductive success through the higher chance of male survival and mating probability of the daughters. To our knowledge, this hypothesis was never confirmed in controlled conditions, although it could have a great impact on the development of a laboratory rearing over several generations. The results obtained in our study using artificial gelatine cells seem close to the findings of Donzé et al. (1996). We similarly found that the reproductive features and the general reproductive success had a tendency to increase under laboratory conditions in the case of double infestation. Both our results and those of Donzé et al. (1996) were obtained outside of the colony in laboratory conditions. The differences between our experiments and the in vivo measurements showing a reduction of the fecundity could again be related to the presence of adult bees. In natural conditions, worker bees could express hygienic or recapping behavior more efficiently towards the multiply infested and highly reproductive cells (Spivak 1996; Harbo and Harris 2009; Harris et al. 2010), which would lead to fewer daughters per foundress. Further studies on hygienic behaviors on singly and multiply infested cells would shed light on this possibility.

Nonetheless, the percentage of cells with males on the 12th day was as hypothesized higher in the case of double infestation than single infestation, which could lead to a higher proportion of mated daughters in doubly infested cells. It should be noted that the difference is reduced when only cells with living daughters are considered. Furthermore, this difference does not explain the greater number of offspring (deutonymphs and daughters) in doubly infested cells found in our study. This finding could be due to the foundress mortality parameter.

In many studies of $V$. destructor reproduction, the frames were frozen so the difference between dead and living females might not have been made with certainty (Ifantidis 1984; Martin 1994; Ifantidis et al. 1999). Our study shows that the mortality of foundresses in doubly and singly infested cells could be an important factor impacting the number of offspring. Indeed, the differences in the number of daughters and more generally of offspring between single and double infestations could rely on the higher chance for a cell to contain a living foundress in the case of double infestation. The presence of a living mother is essential for the development and survival of offspring since the foundress is the only one able to pierce the cuticle to maintain an available feeding site, at least for the first 4 days of the juvenile mites' life (Donzé and Guerin 1994; Martin 1994; Kanbar and Engels 2005). When the foundress is absent, the feeding site heals so the immature parasite stages cannot feed and thus die. We hypothesized that in doubly infested cells, if one of the foundresses dies after initiating its own reproduction, the second one allows the progeny of the dead mother to pursue its development further. This is supported by the fact that the number of offspring in doubly infested cells with only one surviving foundress is on average higher (3.54 \pm $0.67)$ than that observed in singly infested cells $(2.66 \pm 0.23)$. This would result in an overall higher number of females and deutonymphs per foundress in the case of double infestation. On the other hand, we suggest that the number of protonymphs is higher in the single infestation treatment because they cannot feed once the 
mother dies, which would lead to a death at an early stage. This hypothesis on the count of protonymphs should however be considered cautiously as it is not significantly dependent on the foundress survival. Furthermore, at the end of the rearing, some early stages (eggs or protonymphs) are difficult to detect because they can be damaged or covered in waste from the bee molt. These observations require further investigation to confirm that the presence of one living foundress at the end of the rearing is at the origin of the improved reproductive parameters.

To summarize, when only two mites infest the cell, the intra-specific competition between parasites seems low and reduces neither the survival nor the number of offspring per female. The addition of a second mite in our artificial design even seems to improve the reproductive parameters through the development of the progeny which relies on survival of the foundress. If this result is confirmed in nature, it could be interesting to investigate the age of the mites in doubly infested cells. Indeed, one can hypothesize that older mites with a higher mortality risk could be strategically more enticed to double infestation as it would increase the probability of reproductive success even if this old female dies. Despite this reproduction improvement in case of double infestation, the effect of competition on the reproduction of the mite could still appear at higher densities of foundresses (Donzé et al. 1996) or even in doubly infested cells on more subtle aspects of the parasite cycle. The size and fertility of the progeny may be impacted by the competition experienced early in their life, as in the case of parasitoids (Cusumano et al. 2015). The analysis of the mites' daughters in relation to the infestation treatment during their larval development could thus be an interesting path to investigate.

\subsection{Second generation rearing}

Our results revealed that mortality is the main issue when daughters obtained under laboratory conditions are used in a second rearing. Nonetheless, the death of the young adults during their cycle appears to occur after the initiation of reproduction. Indeed, the percentage of reproductive mites $(77.3 \%)$ and the average number of mature daughters per foundress (0.98) are both comparable with the reproductive parameters of the first generation and are within the range of the values from the literature (Martin 1994; Nazzi and Milani 1994; Donzé et al. 1996; Martin et al. 1997; Locke et al. 2012). This is in line with the study of Haußermann et al. (2016) that found that the reproductive parameters in mated daughters artificially reintroduced into larval cells were similar to the reproductive success of phoretic mites. In our rearing, the difference between generations emerges from the death of the laboratory-born mother from the second generation along with their daughters. One hypothesis could be that the increased amount of energy consumed by the reproductive process would weaken the young inexperienced mites. Reproduction is a very energy-consuming process for arthropods such as V. destructor (Cabrera et al. 2013; McAfee et al. 2017; Mondet et al. 2018), and insufficiently matured young females could experience trouble going through their first reproduction. A previous study did reveal that the expression of vitellogenin genes, involved in the energy metabolism during reproduction (Cabrera Cordon et al. 2013), is lower in young females than in their mother at any time of their cycle (Piou et al. 2016). However, this hypothesis was not tested in our study and implies that the initiation of reproduction is more related to a series of signals independent from the female mite and much less related to the energy stocks of the parasite. Although surprising, this is concordant with other observations about the initiation of reproduction (Frey et al. 2013) and with the fact that the fourth (and to a lesser extent the third) egg laid by the female in a worker cell are often observed even though they have no chance of developing into adults (Martin 1994; Donzé et al. 1996; Ifantidis et al. 1999). A second hypothesis would be that the loss of daughters is not related to the energy but to external factors. The low vitellogenin expression could in fact be a sign that the laboratoryborn mites need to mature. In artificial gelatine cells, these young inexperienced females may 
be more fragile and more sensitive to the movements of the emerging bee or to the modifications caused by the bee imaginal molt. They could also be more sensitive to the artificial environment of the laboratory rearing. These hypotheses are not mutually exclusive, and the high amount of energy spent during reproduction could make the young laboratory-born foundresses more sensitive to external stress, which could lead to their death in the most extreme cases. In any case, elucidating the causes of mortality of the laboratory-born females is the next challenge to overcome in order to develop a multigenerational rearing. The artificial introduction of these mites into sealed larval cells of bee colonies (as in Haußermann et al. (2016)) could shed light on the factors leading to the death of young foundresses. Furthermore, in our study, the foundresses from the first generation were not tested in a second laboratory rearing. This should be further investigated as the rearing could also affect the foundress' physiology and disturb their ability to reproduce in a following reproductive cycle.

In conclusion, the experiments described here will help in the development of a laboratory rearing to obtain test mites more easily, especially during periods when they are difficult to find. Based on this study, it appears that artificially infesting the capsules with two mites would increase the number of mated females per foundress only because of the higher probability of having at least one foundress alive to keep the progeny fed. However, when these mated daughters are used in a second rearing, the overall reproductive success decreases even though oviposition and development of the offspring are frequently observed. The fact that the daughters are able to reproduce to levels comparable with those of feral mites is promising. The survival of the second generation, along with the survival and reproduction of foundresses in several successive laboratory cycles, is the next challenge that needs to be addressed. Altogether, our results constitute a first step towards the development of a durable multigenerational laboratory rearing of $V$. destructor.

\section{ACKNOWLEDGMENTS}

We are thankful to Loic Caron and the Association de développement de l'apiculture Occitanie for providing the colonies and for their helpful advice. Many thanks to Dennis Webb for the proofreading of this article.

\section{AUTHORS' CONTRIBUTION}

VP and AV conceived this study; VP designed and performed the experiments, analyzed the results and wrote the manuscript. AV participated in the redaction and revision of the article. All authors read and approved the final manuscript.

\section{FUNDING INFORMATION}

The funding of this study was provided by the Région Occitannie. Vincent Piou is funded by a grant from the Région Occitanie.

\section{COMPLIANCE WITH ETHICAL STANDARDS}

Conflict of interest The authors declare that they have no conflict of interest.

Élevage de Varroa destructor en condition de laboratoire : importance de la survie des femelles fondatrices dans les cellules doublement infectées et reproduction des femelles issues de l'élevage en laboratoire.

Varroa destructor / parasite / mite / élevage en laboratoire / double infestation / multigénérationnel

Varroa destructor-Aufzucht unter Laborbedingungen: Die Bedeutung des Überlebens von Gründerweibchen in doppelinfizierten Zellen und die Reproduktion von Weibchen aus Laboraufzuchten.

Varroa destructor / Parasit / Milbe / Laboraufzucht / Doppelinfizierung / Mehrfachgeneration. 


\section{REFERENCES}

Annoscia, D., Zanni, V., Galbraith, D., Quirici, A., Grozinger, C., Bortolomeazzi, R., Nazzi, F. (2017) Elucidating the mechanisms underlying the beneficial health effects of dietary pollen on honey bees (Apis mellifera ) infested by Varroa mite ectoparasites. Sci. Rep. 7, 6258

Beaurepaire, A. L., Krieger, K. J., Moritz, R. F. A. (2017) Seasonal cycle of inbreeding and recombination of the parasitic mite Varroa destructor in honeybee colonies and its implications for the selection of acaricide resistance. Infect. Genet. Evol. 50, 49-54

Boot, W. J., Calis, J. N. M., Beetsma, J. (1993) Invasion of Varroa jacobsoni into honey bee brood cells: a matter of chance or choice? . J. Apic. Res. 32 (3-4), 167-174

Boot, W. J., Tan, N. Q., Dien, P. C., Huan, L. V., Dung, N. V., Long, L. T., \& Beetsma, J. (1997). Reproductive success of Varroa jacobsoni in brood of its original host, Apis cerana, in comparison to that of its new host, A. mellifera (Hymenoptera: Apidae). Bull. Entomol. Res.87 (02), 119. https://doi.org/10.1017 /s0007485300027255

Cabrera, A. R., Shirk, P. D., Duehl, A. J., Donohue, K. V., Grozinger, C. M., Evans, J. D., Teal, P. E. A. (2013) Genomic organization and reproductive regulation of a large lipid transfer protein in the varroa mite, Varroa destructor (Anderson \& Trueman). Insect Mol. Biol. 22, 505-522

Cabrera Cordon, A. R., Shirk, P. D., Duehl, A. J., Evans, J. D., Teal, P. E. (2013) Variable induction of vitellogenin genes in the varroa mite, Varroa destructor (Anderson \& Trueman), by the honeybee, Apis mellifera L., host and its environment. Insect Mol. Biol. 22 (1), 88-103

Calderón, R.A., Van Veen, J.W., Sommeijer, M.J., Sanchez, L.A. (2010) Reproductive biology of Varroa destructor in Africanized honey bees (Apis mellifera). Exp. Appl. Acarol. 50, 281-297

Calderón, R.A., Urena, S., Van Veen, J.W. (2012) Reproduction of Varroa destructor and offspring mortality in worker and drone brood cells of Africanized honey bees. Exp. Appl. Acarol. 56, 297-307.

Crawley, M. J. (2013) The R book. Chichester, West Sussex, United Kingdom :Wiley

Cusumano, A., Peri, E., Boivin, G., Colazza, S. (2015) Fitness costs of intrinsic competition in two egg parasitoïds of a true bug. J. Insect Physiol. 81, 52-59

Donzé, G., Guerin, P.M. (1994) Behavioral attributes and parental care of Varroa mites parasitizing honeybee brood. Behav. Ecol. Sociobiol. 34, 305-319

Donzé, G., Herrmann, M., Bachofen, B., Guerin, P.M. (1996) Effect of mating frequency and brood cell infestation rate on the reproductive success of the honeybee parasite Varroa jacobsni. Ecol. Entomol. 21 (1), 17-26

Egekwu, N.I., Posada, F., Sonenshine, D.E., Cook, S. (2018) Using an in vitro system for maintaining Varroa destructor mites on Apis mellifera pupae as hosts: studies of mite longevity and feeding behaviour.
Exp. Appl. Acarol., https://doi.org/10.1007/s10493018-0236-0

Eguaras, M., Marcangeli, J., Fernandez, N.A. (1994) Influence of "parasitic intensity" on Varroa Jacobsoni Oud. reproduction. J. Apicult. Res. 33 (3), 155-159

Francis, R.M., Nielsen, S.L., Kryger, P. (2013) Varroavirus interaction in collapsing honey bee colonies. PLoS One, https://doi.org/10.1371/journal.pone57540

Frey, E., Odemer, R., Blum, T., Rosenkranz, P. (2013) Activation and interruption of the reproduction of Varroa destructor is triggered by host signals (Apis mellifera ). J. Invertebr. Pathol., 113 (1), 56-62

Fuchs, S., Langenbach, K. (1989) Multiple infestation of Apis mellifera L. brood cells and reproduction in Varroa jacobsoni Oud. Apidologie 20, 257-266

Goulson, D., Nicholls, E., Botias, C., Rotheray, E.L. (2015) Bee declines driven by combined stress from parasites pesticides, and lack of flowers. Science 347 (6229), 1435-1444

Guzmàn-Novoa, E., Eccles, L., Calvete, Y., McGowan, J., Kelly, P.G., Correa-Benitez, A. (2010) Varroa destructor is the main culprit for the death and reduced populations of overwintered honey bee (Apis mellifera ) colonies in Ontario, Canada. Apidologie 41, 443-450

Harbo, J.R., Harris, J.W. (2009) Responses to Varroa by honey bees with different levels of Varroa Sensitive Hygiene. J. Apic. Res. Bee World 48, 156-161

Harris, J.W., Danka, R.G., Villa, J.D. (2010) Honey bees (Hymenoptera: Apidae) with the trait of Varroa Sensitive Hygiene remove brood with all reproductive stages of Varroa mites (Mesostigmata: Varroidae). Ann. Entomol. Soc. Am. 103(2), 146-152.

Haußermann, C. K., Ziegelmann, B., Rosenkranz, P. (2016) Spermatozoa capacitation in female Varroa destructor and its influence on the timing and success of female reproduction. Exp. Appl. Acarol. 69(4), 371-387

Ifantidis, M. D. (1984). Parameters of the Population Dynamics of the Varroa Mite on Honeybees. J. Apic. Res., 23 (4), 227-233. https://doi.org/10.1080 /00218839.1984.11100637

Ifantidis, M. D., Karamanidou, A., Katikou, P. (1999). Juvenile mortality of the female descendants in the ectoparasite mite Varroa jacobsoni in worker brood of Apis mellifera. J. Apic. Res., 38 (1-2), $25-32$

Kanbar, G., Engels, W. (2005) Communal use of integumental wounds in honey bee (Apis mellifera ) pupae multiply infested by the ectoparasitic mite Varroa destructor. Genet. Mol. Res. 4 (3), 465-472

Le Conte, Y., Arnold, G., Trouiller, J., Masson, C., Chappe, B., Ourisson, G. (1989) Attraction of the parasitic mite Varrroa to the drone larvae of honey bees by simple aliphatic esters. Science 245 (4918), 638-639

Le Conte, Y., Ellis, M., Ritter, W. (2010) Varroa mites and honey bee health: can Varroa explain part of the colony losses ? Apidologie 41, 353-363 
Lin, Z., Qin, Y., Page, P., Wang, S., Li, L., Wen, Z., Hu, F., Neumann, P., Zheng, H., Dietemann, V. (2018) Reproduction of parasitic mites Varroa destructor in original and new honeybee hosts. Ecol. Evol. 8, 21352145

Locke, B., Le Conte, Y., Crauser, D., Fries, I. (2012) Host adaptations reduce the reproductive success of Varroa destructor in two distinct European honey bee populations. Ecol. Evol. 2 (6), 1144-1150

Martin, S.J. (1994) Ontogenesis of the mite Varroa jacobsoni Oud. in worker brood of the honeybee Apis mellifera L. under natural conditions. Exp. Appl. Acarol. 18, 87-100

Martin, S.J. (1995) Reproduction of Varroa jacobsoni in cells of Apis mellifera containing one or more mother mites and the distribution of the cells. J. Apic. Res. 34 (4), 187-196

Martin, S.J. (2001) The role of Varroa and viral pathogens in the collapse of honeybee colonies: a modelling approach. J. Appl. Ecol. 38, 1082-1093

Martin, S., Holland, K., Murray, M. (1997) Nonreproduction in the honeybee mite Varroa jacobsoni. Exp. Appl. Acarol. 21, 539-549

Martin, S.J., Kemp, D. (1997) Average number of reproductive cycles performed by Varroa jacobsoni in honey bee (Apis mellifera) colonies. J. Apic. Res. 36 (3-4), 113-123

McAfee, A., Chan, Q.W.T., Evans, J., Foster, L.J. (2017) A Varroa destructor protein atlas reveals molecular underpinnings of developmental transitions and sexual differentiation. Mol. Cell. Proteomics 16,2125-37

Medina, L.M., Martin, S.J. (1999) A comparative study of Varroa jacobsoni reproduction in worker cells of honey bees (Apis mellifera) in England and Africanized bees in Yucatan, Mexico. Exp. Appl. Acarol. 23, 659667

Mondet, F., Rau, A., Klopp, C., Rohmer, M., Severac, D., Le Conte, Y., Alaux, C. (2018) Transcriptome profiling of the honeybee parasite Varroa destructor provides new biological insights into the mite adult life cycle. BMC Genomics, https://doi.org/10.1186 /s12864-018-4668-Z

Nazzi, F., Le Conte, Y. (2015) Ecology of Varroa destructor, the major ectoparasite of the Western honey bee, Apis mellifera. Annu. Rev. Entomol. 61, 417432

Nazzi, F., Milani, N. (1994) A technique for reproduction of Varroa jacobsoni Oud. under laboratory conditions. Apidologie 25, 579-579

Neumann, P., Carreck, N.L. (2010) Honey bee colony losses. J. Apic. Res. 49 (1), 1-6

Nganso, B.T., Fombong, A.T., Yusuf, A.A. (2018) Low fertility, fecundity and numbers of mated female offspring explain the lower reproductive success of the parasitic mite Varroa destructor in African honeybees. Parasitology 145, 1633-1639, https://doi.org/10.1017 /S0031182018000616
Oddie, M., Büchler, R., Dahle, B., Kovacic, M., Le Conte, Y., Locke, B., de Miranda, J.R., Mondet, F., Neumann, P. (2018) Rapid parallel evolution overcomes global honey bee parasite. Sci. Rep. 8, 7704 https://doi. org/10.1038/s41598-018-26001-7

Odemer, R. (2020) Reproductive capacity of Varroa destructor in four different honey bee subspecies. Saudi J. Biol. Sci. 27, 247-250

Oldroyd, B.P. (2007) What's killing American honey bees? PLoS Biol. 5 (6), 1195-1198

Pain, J. (1966) Nouveau modèle de cagettes expérimentales pour le maintien d'abeilles en captivité. Ann. Abeille, 9 (1), 71-76.

Piou, V., Tabart, J., Urrutia, V., Hemptinne, J-L., Vétillard, A. (2016) Impact of the phoretic phase on reproduction and damage caused by Varroa destructor (Anderson and Trueman) to its host, the European honey bee (Apis mellifera L.). PLoS One, https://doi. org/10.1371/journal.pone.0153482

R Core Team (2017). R: A language and environment for statistical computing. R Foundation for Statistical Computing, Vienna, Austria. URL https://www.R-project.org/.

Rehm, S. M., Ritter, R. (1989) Sequence of the sexes in the offspring of Varroa jacobsoni and the resulting consequences for the calculation of the developmental period. Apidologie, 20 (4), 339-343

Rosenkranz, P., Aumeier, P., Ziegelmann, B. (2010) Biology and control of Varroa destructor. J. Invertebr. Pathol. 103, 96-119

Solignac, M., Cornuet, J-M., Vautrin, D., Le Conte, Y., Anderson, D., Evans, J., Cros-Arteil, S., Navajas, M. (2005) The invasive Korea and Japan types of Varroa destructor, ectoparasitic mites of the Western honeybee (Apis mellifera), are two partly isolated clones. Proc. R. Soc. B Biol. Sci., 272, 411-419

Spivak, M. (1996) Honey bee hygienic behaviour and defense against Varroa jacobsoni. Apidologie 27, 245-260

Tabart, J., Colin, ME., Carayon, JL., Tene, N., Payre, B., Vetillard, A. (2013) Artificial feeding of Varroa destructor through a chitosan membrane: a tool for studying the host-microparasite relationship. Exp. Appl. Acarol. 6(1), 107-118

Wickham H. (2009). ggplot2: Elegant Graphics for Data Analysis. Springer-Verlag New York

Ziegelmann, B., Lindenmayer, A., Steidle, J., Rosenkranz, P. (2013) The mating behavior of Varroa destructor is triggered by a female sex pheromone. Part 1: Preference behavior of male mites in a laboratory bioassay. Apidologie 44 (3), 314-323

Publisher's note Springer Nature remains neutral with regard to jurisdictional claims in published maps and institutional affiliations. 